\title{
Adrenaline before Unconventional Therapy for Status Asthamaticus
}

\author{
Jayendra R Gohil \\ Indian Journal of Critical Care Medicine (2019): 10.5005/jp-journals-10071-23273
}

Sir,

Refractory Status Asthmaticus: A Case for Unconventional Therapies, article by Vohra $\mathrm{R}$ has mentioned survival of a child after using ECMO and isoflurane when other treatments were not effective. ' History of food ingestion prior to onset of status is not mentioned as there are foods like dairy, nuts, seafood, eggs, and pollution and color, that may precipitate an acute episode.

In the treatment however, inj. adrenaline and inj. hydrocortisone were not used; although intravenous methylprednisolone ( $2 \mathrm{mg} /$ $\mathrm{kg}$ ) was used. Intramuscular adrenaline is having better absorption and quicker effects than subcutaneous route. ${ }^{2}$ Ipratropium is an atropine like drug and leads to thickening of secretions and mucus plugging and have to be removed by bronchoscopy lavage.

Injections of adrenaline and hydrocortisone should be administered before resorting to ECMO and isoflurane.

\section{References}

1. Vohra R, Sachdev A, Gupta D, Gupta N, Gupta S. Refractory status asthmaticus: A case for unconventional therapies. Indian J Crit Care Med 2018;22(10):749-752.
Department of Pediatrics, Government Medical College, Sir T Hospital, Bhavnagar, Gujarat, India

Corresponding Author: Jayendra R Gohil, Department of Pediatrics, Government Medical College, Sir T Hospital, Bhavnagar, Gujarat, India, Phone: 91-278-2429540, +91-9824090049, 9426348908, e-mail: jayukids@yahoo.com.

How to cite this article: Gohil JR. Adrenaline before Unconventional Therapy for Status Asthamaticus. Indian J Crit Care Med 2019; 23(10):492.

Source of support: Nil

Conflict of interest: None

2. Gohil J, Agarwal TS. Anaphylaxis and Angioedema: A of ABC means Adrenaline First: Airway comes Later. J Asso Physicians India. 2018;66(10):76.

(0) The Author(s). 2019 Open Access This article is distributed under the terms of the Creative Commons Attribution 4.0 International License (https://creativecommons. org/licenses/by-nc/4.0/), which permits unrestricted use, distribution, and non-commercial reproduction in any medium, provided you give appropriate credit to the original author(s) and the source, provide a link to the Creative Commons license, and indicate if changes were made. The Creative Commons Public Domain Dedication waiver (http://creativecommons.org/publicdomain/zero/1.0/) applies to the data made available in this article, unless otherwise stated. 